\title{
Molecular thrombophilic profile in Mexican patients with idiopathic recurrent pregnancy loss
}

\author{
J.J. López-Jiménez ${ }^{1}$, Á. Porras-Dorantes ${ }^{2,3}$, C.I. Juárez-Vázquez ${ }^{2,3}$, \\ J.E. García-Ortiz ${ }^{2}$, C.A. Fuentes-Chávez ${ }^{2,4}$, I.J. Lara-Navarro ${ }^{2,3}$ and \\ A.R. Jaloma-Cruz ${ }^{2}$ \\ ${ }^{1}$ División de Medicina Molecular, \\ Centro de Investigación Biomédica de Occidente, IMSS, Guadalajara, \\ Jalisco, México \\ ${ }^{2}$ División de Genética, Centro de Investigación Biomédica de Occidente, \\ IMSS, Guadalajara, Jalisco, México \\ ${ }^{3}$ Centro Universitario de Ciencias de la Salud, Universidad de Guadalajara, \\ Guadalajara, Jalisco, México \\ ${ }^{4}$ Escuela de Ciencias, Departamento de Ciencias Químico-Biológicas, \\ Universidad de las Américas, Cholula, Puebla, México \\ Corresponding author: A.R. Jaloma-Cruz \\ E-mail: arjaloma@gmail.com
}

Genet. Mol. Res. 15 (4): gmr.15048728

Received April 25, 2016

Accepted June 16, 2016

Published October 5, 2016

DOI http://dx.doi.org/10.4238/gmr.15048728

Copyright (C) 2016 The Authors. This is an open-access article distributed under the terms of the Creative Commons Attribution ShareAlike (CC BY-SA) 4.0 License.

ABSTRACT. Idiopathic recurrent pregnancy loss (IRPL) is defined by
three or more consecutive miscarriages occurring before the twentieth
week of gestation as a result of unidentified etiological factors. The
results of previous studies have indicated that prothrombotic factors
play a pathogenic role in early and late pregnancy. This study aimed
to identify inherited prothrombotic and hypofibrinolytic risk factors

Genetics and Molecular Research 15 (4): gmr.15048728 
in Mexican-Mestizo patients with IRPL. Fifty-six women with IRPL and 50 control women with at least two full-term pregnancies and no history of RPL were included in this case-control study. Four prothrombotic (F5 G1691A, F2 G20210A, MTHFR C677T-A1298C) and one hypofibrinolytic (PAI1 4G/5G) restricted fragment length polymorphisms were subjected to molecular analysis. In the case of hypofibrinolytic ACE Ins/Del (I/D), identification was performed by direct PCR. The independent risk correlated with the presence of polymorphisms in IRPL patients was estimated using odds ratio (OR) with a 95\% confidence interval (CI). MTHFR $677 \mathrm{TT}$ was the most frequent prothrombotic factor in the IRPL group (23\%), followed by the compound-heterozygous C677T-A1298C (16\%) and heterozygous F2 20210GA (3.6\%). The heterozygous $A C E$ I/D (62\%) was the main hypofibrinolytic risk factor of IRPL, followed by the homozygote PAII 4G/4G (18\%). The $A C E \mathrm{I} / \mathrm{D}$ polymorphism was the only significantly different factor among the cases and controls. The dominant genetic model D/D+I/D vs I/I showed an OR $(95 \% \mathrm{CI})$ of $2.89(1.22-6.89)$ and $\mathrm{P}=0.019$ in Mexican-Mestizo women. The results of this study support an association between the $A C E \mathrm{I} / \mathrm{D}$ polymorphism and IRPL risk in a Mexican population.

Key words: $A C E I / D$ polymorphism; Gene-disease association; Hypofibrinolysis; Recurrent pregnancy loss; Thrombophilia

\section{INTRODUCTION}

Recurrent pregnancy loss (RPL), initially defined as "three or more consecutive miscarriages before the 20th week of gestation", has been reported to affect $1-2 \%$ of reproductive-age females (Bashiri et al., 2012). Over the years, this definition has been updated to "two or more pregnancy losses"; consequently, there has been an increase in the frequency of reproductive-age women with RPL to 1-5\% (Bashiri et al., 2012). RPL has a multifactorial etiology including a wide spectrum of abnormalities; causative risk factors of RPL include anatomic, immune, endocrine, infectious, chromosomal, and environmental factors, and inherited or acquired thrombophilia (Kiwi, 2006; Thomas and van der Spuy, 2010; Bennett et al., 2012). Idiopathic RPL (IRPL) is defined in $~ 50 \%$ of the couples seeking diagnosis who present none of the above etiological factors (Thomas and van der Spuy, 2010).

Evidence from previous control trials, cohort studies, and meta-analyses has supported that inherited prothrombotic factors play a pathogenic role in early and late pregnancy, in effect, causing a thrombogenic physiological state (Bennett et al., 2012).

Thrombosis, and its clinical manifestations, can be attributed to a large number of deaths worldwide. Thrombosis arises because of an imbalance between thrombogenic factors and antithrombotic mechanisms (including fibrinolysis) (Rosenberg and Aird, 1999). Rosendaal (1999) described this phenomenon as a multicausal disease. Thrombus formation can appear at various levels of vascular integrity, affecting veins and arteries, as well as the fetal-maternal circulatory system, resulting in miscarriage (Bennett et al., 2012). Arterial thrombosis is a major cause of death worldwide every year. Alternately, 1 in 1000 individuals

Genetics and Molecular Research 15 (4): gmr.15048728 
are afflicted with deep venous thrombosis (Rosendaal, 1999). Women with thrombophilia caused by individual (or a combination of) defects in antithrombin, protein $\mathrm{C}$, or protein $\mathrm{S}$ production are at an increased risk of fetal loss, possibly leading to RPL (Preston et al., 1996).

Inherited thrombophilia induces abnormal coagulation in the utero-placental circulation during the early stages of pregnancy or an increased predisposition to placental infections, leading to late fetal loss, intrauterine growth retardation, and abruptio placentae (Kiwi, 2006).

In particular, approximately $15 \%$ of all women with RPL are afflicted with primary thrombophilia caused by the G1691A (FV Leiden or dbSNP: rs6025), G20210A (dbSNP: rs1799963), and C677T (dbSNP: rs1801133) combined with deficiency of natural anticoagulant (antithrombin, C protein, and S protein) (Kiwi, 2006; Bennett et al., 2012). Several studies have reported an association between $F 5$ G1691A and F2 G20210A polymorphisms and RPL, primarily during the first trimester, and late non-recurrent fetal loss (Bennett et al., 2012). According to various meta-analyses, mild hyperhomocysteinemia (HHC) is a risk factor for thrombosis in the presence of low plasma folate levels (Boushey et al., 1995; den Heijer et al., 1998). Likewise, HHC is strongly associated with recurrent early pregnancy loss, whereas the association between the C677T mutation related to HHC and RPL is controversial because of a dependent intake of folates and B vitamins (Nelen et al., 2000; Rey et al., 2003).

The association between the A1298C polymorphism (dbSNP: rs1801131) in MTHFR and RPL is also controversial. Nair et al. (2013) concluded that the presence of the A/C and $\mathrm{C} / \mathrm{C}$ genotypes significantly increased the risk of RPL in an Indian population based on the results of their meta-analysis. However, another meta-analysis indicated that the A1298C polymorphism in MTHFR is not a risk factor for RPL (Rai, 2014).

Mutations in antifibrinolytic factors, as well as those in pro-coagulant factors, have been associated with RPL ( $\mathrm{Su}$ et al., 2013). Normal fibrinolysis prevents excess fibrin deposition in the placental and fetal vasculature; moreover, fibrin polymerization stabilizes the placental basal plate (Su et al., 2013). The angiotensin I-converting enzyme Ins/Del ( $A C E \mathrm{I} / \mathrm{D})$ and plasminogen activator inhibitor-1 (PAI1) 4G/5G polymorphisms, associated with low fibrinolysis, and their synergistic physiological effect on thrombosis, have also been extensively studied. ACE converts angiotensin I to angiotensin II, a potent vasoconstrictor that promotes vasoconstriction, inflammation, and thrombosis in the vascular endothelium and vessel walls (Su et al., 2013). Angiotensin II is a proatherogenic agent, which elevates the level of PAI-1, resulting in decreased fibrinolytic activity. Recent studies have indicated the important contribution of these hypofibrinolytic factors in the etiology of RPL (Su et al., 2013).

The $A C E \mathrm{I} / \mathrm{D}$ polymorphism is involved in maternal uteroplacental and fetal circulation, thereby affecting the outcome of pregnancy (Mello et al., 2003). Previous metaanalyses have indicated that IRPL is strongly associated with the I/D polymorphism in $A C E$ (dbSNP: rs4340). In fact, both the $\mathrm{D} / \mathrm{D}$ and $\mathrm{I} / \mathrm{D}$ genotypes have been shown to increase the risk of RPL by 29\% (Su et al., 2013; Wang et al., 2013).

On the other hand, two previous meta-analyses have provided conflicting results regarding the association between the 4G/5G polymorphism in PAI1 (dbSNP: rs587776796) and RPL (Sotiriadis et al., 2007; Su et al., 2013). RPL must be carefully studied in diverse ethnic populations to elucidate the role of the PAIl 4G/5G in preventing RPL ( $\mathrm{Su}$ et al., 2013). Neither of these meta-analyses has included RPL patients from the Mexican-Mestizo population (Sotiriadis et al., 2007; Su et al., 2013).

Genetics and Molecular Research 15 (4): gmr.15048728 
The main objective of this study was to identify inherited thrombophilia markers (polymorphisms in prothrombotic and hypofibrinolytic risk factors) in patients with IRPL, and compare the results with those seen in a control group of women with normal pregnancy. This is the first study of this kind conducted in Mexico.

\section{MATERIAL AND METHODS}

\section{Inclusion criteria for case and control groups}

Fifty-six patients with IRPL (defined as three consecutive pregnancy losses prior to the 20th week of gestation), identified from a clinical database comprising 124 RPL MexicanMestizo patients, were included in this study. IRPL was diagnosed in the included patients after an exhaustive screening process to rule out RPL caused by secondary factors.

Patients with ectopic pregnancies or unfavorable anatomic factors, such as cervical insufficiency, intrauterine adhesion, uterine fibroids, and uterine polyps, were ruled out. The included patients tested negative for antiphospholipids, anti-DNA, and antinuclear and anticardiolipin antibodies. Lupus-like anticoagulants were used to rule out acquired thrombophilia due to lupus and antiphospholipid syndrome. Multiple-standard laboratory tests were performed to rule out endocrinal causes of RPL, including hyperthyroidism, hypothyroidism, hyperprolactinemia, luteal insufficiency, and diabetes. The patients were also tested for the TORCH panel, and subjected to vaginal screening (for bacteria and fungi), to rule out the presence of infectious diseases. Chromosomal abnormalities, including translocation, trisomy, and triploidy, were evaluated by cytogenetics experts. Fifty women with at least two normal full-term pregnancies and no more than one gestational loss were recruited as controls. The clinical, demographic, and hereditary information was obtained from all recruited individuals via a structured questionnaire. The included individuals were confirmed to be unrelated up to the previous two generations.

\section{Molecular analysis}

The thrombophilic marker profiles of the recruited IRPL patients and control subjects were constructed by analyzing the following RFLPs in these populations: F5 G1691A, F2 G20210A, MTHFR C677T-A1298C, PAI1 4G/5G. The ACE I/D marker was assessed in only 55 IRPL patients. Blood samples were collected from all patients and control subjects in EDTA-Na $\mathrm{N}_{2}$ tubes, and genomic DNA was purified from the peripheral blood leukocytes $(10 \mathrm{~mL})$ using a standard salting-out method (Miller et al., 1988). The selected markers were genotyped using previously described methods: F5 G1691A, F2 G20210A (Ripoll et al., 1997), MTHFR C677T (Frosst et al., 1995), MTHFR A1298C (van der Put et al., 1998), ACE I/D (Rigat et al., 1992), and PAI1 4G/5G (Isordia et al., 2009). The genotypes were identified by polyacrylamide gel electrophoresis (PAGE; 29:1, 6\%) and stained by silver nitrate. The samples were genotyped at CIBO, IMSS (Guadalajara, Mexico).

\section{Statistical analysis}

Non-parametric statistical analyses, including the Fisher exact test and the Pearson chi-square exact test, were performed using SPSS v.22 for Windows (IBM, Armonk, NY,

Genetics and Molecular Research 15 (4): gmr.15048728 
USA). Independent risk of IRPL as a result of polymorphisms in various thrombotic factors was estimated by odds ratio (OR) and its $95 \%$ confidence interval (CI). The conformance of genetic markers in the control group with the Hardy-Weinberg equilibrium was also analyzed.

\section{Ethical considerations}

Written informed consent was obtained from all IRPL patients and control individuals prior to the study. All procedures and DNA sample collection were performed in accordance with the principles of the Helsinki Declaration, and were approved by the Institutional Scientific and Ethics Committee (registration number R-2010-1305-3).

\section{RESULTS}

The control subjects were age-matched with the patients with IRPL. The clinical and demographic characteristics of the controls and patients with IRPL are summarized in Table 1. The gravidity traits were also compared among the two groups (Table 1).

\begin{tabular}{|c|c|c|}
\hline Clinical/demographic data & Mean (range) & \\
\hline $\begin{array}{l}\text { IRPL group }(\mathrm{N}=55) \\
\text { Gravidity (cumulative total, } \mathrm{N}=203 \text { ) }\end{array}$ & $4(2-6)$ & \\
\hline $\begin{array}{l}\text { Control group }(\mathrm{N}=50) \\
\text { Gravidity (cumulative total, } \mathrm{N}=187 \text { ) }\end{array}$ & $3(1-4)$ & \\
\hline IRPL group ( $\mathrm{N}=47)$, age (years) & $30(18-41)$ & \\
\hline Control group $(\mathrm{N}=50)$, age (years) & $30(18-42)$ & \\
\hline IRPL group $(\mathrm{N}=49), \mathrm{BMI}\left(\mathrm{kg} / \mathrm{m}^{2}\right)$ & $27.6(19-45)$ & \\
\hline $\begin{array}{l}\text { IRPL group }(\mathrm{N}=55) \text { GWMO } \\
(\text { cumulative group total weeks, } \mathrm{N}=1406)\end{array}$ & $9(5-15)$ & \\
\hline Miscarriage (M)/Parity (P) & $\mathrm{M}[\mathrm{N}(\%)] / \mathrm{P}[\mathrm{N}(\%)]$ & \multirow{3}{*}{$\begin{array}{l}\text { P value }{ }^{\mathrm{a}} \\
<0.001\end{array}$} \\
\hline $\begin{array}{l}\text { IRPL group, total gravidity }(\mathrm{N}=203) \\
\text { Miscarriage/Parity }\end{array}$ & $161(79) / 42(21)$ & \\
\hline $\begin{array}{l}\text { Control group, total gravidity }(\mathrm{N}=187) \\
\text { Miscarriage/Parity }\end{array}$ & $8(4) / 179(96)$ & \\
\hline
\end{tabular}

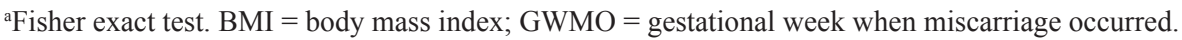

The results of the molecular analyses (of the IRPL patients and the control subjects) are summarized in Table 2. The prothrombotic factor MTHFR 677TT was most frequently observed in IRPL patients (23\%), followed by the compound-heterozygous MTHFR C677TA1298C (16\%) and the heterozygous F2 20210GA (3.6\%) mutations (Table 2). The major hypofibrinolytic risk factor of IRPL was found to be the heterozygote genotype of $A C E$ (I/D) (62\%), followed by the homozygote genotype of PAIl (4G/4G; 18\%) (Table 2).

We found no statistically significant differences in the genotype expression of the prothrombotic factors F5 G1691A, F2 G20210A, and MTHFR C677T-A1298C between the IRPL and control groups. However, the frequency of the heterozygous genotype of the I/D polymorphism in the hypofibrinolytic factor $A C E I / D$ was significantly different $(\mathrm{P}=0.031)$ between the IRPL patients and control subjects. Conversely, the genotype frequencies of the PAI1 4G/5G polymorphism did not differ significantly among the two groups (Table 2 ). The dominant genetic model D/D+I/D vs I/I (of $A C E \mathrm{I} / \mathrm{D})$ had an OR (95\%CI) of 2.89 (1.22-6.89) $(\mathrm{P}=0.019)$ in the analyzed Mexican-Mestizo population. 


\begin{tabular}{|c|c|c|c|}
\hline & IRPL group $(\mathrm{N}=56)$ & Control group $(\mathrm{N}=50)$ & $P$ value \\
\hline \multicolumn{4}{|c|}{ F5 G1691A [N (\%)] } \\
\hline $\mathrm{A} / \mathrm{G}$ & $1(1.8)$ & $1(2)$ & \multirow[t]{2}{*}{$>0.99^{\mathrm{a}}$} \\
\hline $\mathrm{G} / \mathrm{G}$ & $55(98.2)$ & $49(98)$ & \\
\hline \multicolumn{4}{|c|}{$F 2$ G20210A [N (\%)] } \\
\hline $\mathrm{A} / \mathrm{G}$ & $2(3.6)$ & $2(4)$ & \multirow[t]{2}{*}{$>0.99^{\mathrm{a}}$} \\
\hline $\mathrm{G} / \mathrm{G}$ & $54(96.4)$ & $48(96)$ & \\
\hline \multicolumn{4}{|c|}{ MTHFR C677T [N (\%)] } \\
\hline $\mathrm{C} / \mathrm{C}$ & $17(30.4)$ & $12(24)$ & \multirow[t]{3}{*}{$0.657^{\mathrm{b}}$} \\
\hline $\mathrm{C} / \mathrm{T}$ & $26(46.4)$ & $23(46)$ & \\
\hline $\mathrm{T} / \mathrm{T}$ & $13(23.2)$ & $15(30)$ & \\
\hline \multicolumn{4}{|c|}{ MTHFR A1298C [N (\%)] } \\
\hline $\mathrm{A} / \mathrm{A}$ & $42(75)$ & $37(74)$ & \multirow[t]{3}{*}{$0.907^{\mathrm{b}}$} \\
\hline $\mathrm{A} / \mathrm{C}$ & $13(23)$ & $13(26)$ & \\
\hline $\mathrm{C} / \mathrm{C}$ & $1(2)$ & $0(0)$ & \\
\hline \multicolumn{4}{|c|}{ MTHFR C677T-A1298C [N (\%)] } \\
\hline $\mathrm{C} / \mathrm{T}+\mathrm{A} / \mathrm{C}$ & $9(16.1)$ & $8(16)$ & \multirow[t]{3}{*}{$>0.99^{\mathrm{b}}$} \\
\hline $\mathrm{T} / \mathrm{T}+\mathrm{A} / \mathrm{C}$ & $1(1.8)$ & $0(0)$ & \\
\hline $\mathrm{C} / \mathrm{C}+\mathrm{A} / \mathrm{A}+\mathrm{C} / \mathrm{C}$ & $46(82.1)$ & $42(84)$ & \\
\hline \multicolumn{4}{|c|}{$P A I I$ 4G/5G [N (\%)] } \\
\hline $4 \mathrm{G} / 4 \mathrm{G}$ & $10(17.9)$ & $7(14)$ & \multirow[t]{3}{*}{$0.444^{\mathrm{b}}$} \\
\hline $4 \mathrm{G} / 5 \mathrm{G}$ & $25(44.6)$ & $18(36)$ & \\
\hline $5 \mathrm{G} / 5 \mathrm{G}$ & $21(37.5)$ & $25(50)$ & \\
\hline$A C E \mathrm{I} / \mathrm{D}[\mathrm{N}(\%)]$ & IRPL patients $(\mathrm{N}=55)$ & & \multirow{4}{*}{$0.031^{\mathrm{b}}$} \\
\hline $\mathrm{D} / \mathrm{D}$ & $10(18)$ & $10(20)$ & \\
\hline $\mathrm{D} / \mathrm{I}$ & $34(62)$ & $19(38)$ & \\
\hline $\begin{array}{l}\mathrm{I} / \mathrm{I} \\
\end{array}$ & $11(20)$ & $21(42)$ & \\
\hline
\end{tabular}

a Fisher exact test. ${ }^{b}$ Exact results of Pearson chi-square test.

\section{DISCUSSION}

RPL has a multifactorial etiology; in some cases, therefore, it is not possible to identify its cause. A large number of recurrent pregnancy losses are idiopathic. Forty-five percent of the analyzed cases $(\mathrm{N}=124)$ presented IRPL, which was similar to a previously reported percentage of IRPL cases (50\%) (Thomas and van der Spuy, 2010).

Pregnancy has been recognized as a hypercoagulable state; therefore, concomitant thrombophilic risk factors may enhance the thrombotic risk and impair fetal circulation, or cause thrombotic vasculopathy in the placenta, resulting in fetal loss (Bennett et al., 2012; $\mathrm{Su}$ et al., 2013). The low frequencies of prothrombotic factors F5 G1691A and F2 G20210A observed in the IRPL group (1.8 and 3.6\%, respectively) were consistent with the reported frequencies in a review of diverse RPL populations (Bradley et al., 2012). The frequencies of these factors did not differ significantly between patients with IRPL and control individuals (women without IRPL). This result was similar to that reported in Mexican-Mestizo RPL patients by Quintero-Ramos et al. (2006), whose control group was comprised of normal women and men belonging to the same geographic region as included in our study. In contrast, Bradley et al. (2012) reported a significant association between the two groups in their review, wherein the OR was $\sim 2$ for both mutations in RPL patients (Bradley et al., 2012).

Elevated homocysteine levels due to mutations in MTHFR have been reported as risk factors for the pathogenesis of RPL; however, there has been no consensus regarding the association between MTHFR polymorphisms and IRPL (Cao et al., 2013). In this study, the $677 \mathrm{TT}$ and $1298 \mathrm{CC}$ genotypes were found at frequencies of 23 and $2 \%$ in the IRPL

Genetics and Molecular Research 15 (4): gmr.15048728 
patients, respectively. The 677TT genotype was the most frequent prothrombotic risk factor in women with IRPL; however, the genotype distributions of the MTHFR 677TT and 1298CC polymorphisms were not significantly different between the case and control groups. Cao et al. (2013) reported the highest OR (2.1) for the 677TT genotype in Asian women with IRPL; however, the MTHFR $1298 \mathrm{CC}$ polymorphism was not significant, consistent with previous meta-analyses (Cao et al., 2013; Rai, 2014). This result was also similar to that reported by Quintero-Ramos et al. (2006). However, the results reported by Rodríguez-Guillén et al. (2009) in a small group (23 cases) of Mexican women with spontaneous abortion and 74 normal controls were different; for example, these authors reported high ORs for the 677TT and 1298AC genotypes (5 and 5.5, respectively). Previous reports have suggested that compound heterozygous $677 \mathrm{CT} / 1298 \mathrm{AC}$ individuals express 50\% MTHFR activity, similar to those individuals with homozygous MTHFR 677TT (Weisberg et al., 1998). The frequency of the compound heterozygous genotype of MTHFR is reportedly very high in IRPL cases (16.1\%), but did not differ significantly from the frequency observed in the control group (Zetterberg et al., 2002; Mtiraoui et al., 2006).

Early human trophoblastic invasion is regulated by the fibrinolytic system; plasmin promotes trophoblastic invasion by activating matrix metalloproteinases that directly degrade various components of the extracellular matrix of the decidua. Thus, hypofibrinolytic factors can lead to IRPL.

The renin-angiotensin system (RAS) is activated in normal pregnancy, and the levels of involved proteins, such as angiotensinogen, angiotensin II, and aldosterone, are markedly elevated. Moreover, angiotensin II levels are modulated by ACE (Su et al., 2013). Uteroplacental and fetal umbilical circulation are dependent on the RAS system; moreover, Mello et al. (2003) suggested that the I/D polymorphism in $A C E$ induces abnormal hypertensive maternal uteroplacental and fetal umbilical flow.

The most common risk factor for IRPL in our population was the heterozygote genotype $A C E \mathrm{I} / \mathrm{D}(62 \%)$; this frequency was significantly different from that seen in the control group (Table 2) under a dominant genetic model. The $\mathrm{OR}$ of the $A C E \mathrm{D} / \mathrm{D}+\mathrm{I} / \mathrm{D}$ vs $\mathrm{I} / \mathrm{I}$ model was $2.89(95 \% \mathrm{CI}=1.22-6.89 ; \mathrm{P}=0.019)$. These data are concordant with the data obtained by Su et al. (2013) in a previous meta-analysis conducted in RPL patients (OR of a dominant genetic model $=1.29 ; 95 \% \mathrm{CI}=1.02-1.62)$, which indicated a significant association between the $A C E \mathrm{I} / \mathrm{D}$ polymorphism and RPL; moreover, women carrying the $\mathrm{D} / \mathrm{D}$ or I/D genotypes were found to be at a $29 \%$ higher risk of developing RPL, compared to those expressing the I/I genotype (Su et al., 2013). This supports our results, as well as those reported by Wang et al. (2013), who established a dominant genetic model of the $A C E \mathrm{I} / \mathrm{D}$ polymorphic variants contributing to RPL susceptibility ( summary OR $=1.44 ; 95 \% \mathrm{CI}=1.05$ 1.97). However, Quintero-Ramos et al. (2006) reported that the genotype distribution of the $A C E$ I/D polymorphism did not differ significantly between IRPL patients (idiopathicity not exhaustively described) and normal Mexican-Mestizo controls. The differences between our results and those reported by Quintero-Ramos et al. (2006) could be attributed to the inclusion of both male and female individuals in their control group ( $>200)$, compared to our womanonly (expressing a successful pregnancy phenotype) control population.

Despite the role played by PAI-1 in inhibiting fibrinolysis, and the effect of the $4 \mathrm{G} / 4 \mathrm{G}$ polymorphism in PAII on the PAI-1 levels, polymorphisms in the marker have not been associated with RPL in previous meta-analyses (Sotiriadis et al., 2007; Su et al., 2013), similar to the results seen in our IRPL study population. The frequency of the homozygous $4 \mathrm{G} / 4 \mathrm{G}$

Genetics and Molecular Research 15 (4): gmr.15048728 
and heterozygous $4 \mathrm{G} / 5 \mathrm{G}$ genotypes in PAIl was quite high in the IRPL population (17.9 and $44.6 \%$, respectively); this was concordant with the results reported by Flores-Alatriste et al. (2014) in a Mexican population with RPL (homozygous 4G/4G and heterozygous 4G/5G frequencies $=22$ and $63 \%$, respectively).

The results of this study were similar to those of previous meta-analyses ( $\mathrm{Su}$ et al., 2013; Wang et al., 2013) reporting an association between the $A C E$ I/D polymorphism and IRPL; this could be attributed to the role of ACE in uteroplacental and fetal umbilical circulation. However, this polymorphism is only a partial contributor $(29 \%)$ to RPL, which is a polygenic condition (Su et al., 2013). Therefore, related genetic components, such as those involved in angiogenesis (leading to the establishment of feto-placental circulation), must be studied further. Samli et al. (2012) reported a significant association between the 1154 G/A polymorphism in the vascular endothelial growth factor gene (VEGF) and RLP. Future studies into polymorphisms occurring in factors influencing thrombophilia and angiogenesis would help confirm the role of impaired utero-fetal circulation in IRPL.

In conclusion, this is the first case-control study of prothrombotic and hypofibrinolytic genetic markers of IRPL in a Mexican Mestizo population. We observed a significant association $(\mathrm{P}=0.019)$ between the $A C E \mathrm{I} / \mathrm{D}$ polymorphic variant and risk of idiopathic recurrent pregnancy loss. Further well-designed studies with adequate inclusion criteria and cohorts are required to identify various genetic haplogroups of prothrombotic and hypofibrinolytic risk factors, the genetic factors affecting uteroplacental and fetal umbilical flows, and the alterations in various environmental elements involved in trophoblast invasion, which are some of the major causative factors of IRPL.

\section{Conflicts of interest}

The authors declare no conflict of interest.

\section{ACKNOWLEDGMENTS}

The authors would like to acknowledge the valuable support provided by Alejandra Hernández (Laboratory Technician) in obtaining the DNA samples and performing molecular diagnostic procedures. Sharon Morey (Scientific Communications) assisted in the English editorial review.

\section{REFERENCES}

Bashiri A, Ratzon R, Amar S, Serjienko R, et al. (2012). Two vs. three or more primary recurrent pregnancy losses - are there any differences in epidemiologic characteristics and index pregnancy outcome? J. Perinat. Med. 40: 365-371. http://dx.doi.org/10.1515/jpm-2011-0295

Bennett SA, Bagot CN and Arya R (2012). Pregnancy loss and thrombophilia: the elusive link. Br. J. Haematol. 157: 529542. http://dx.doi.org/10.1111/j.1365-2141.2012.09112.x

Boushey CJ, Beresford SA, Omenn GS and Motulsky AG (1995). A quantitative assessment of plasma homocysteine as a risk factor for vascular disease. Probable benefits of increasing folic acid intakes. JAMA 274: 1049-1057. http:// dx.doi.org/10.1001/jama.1995.03530130055028

Bradley LA, Palomaki GE, Bienstock J, Varga E, et al. (2012). Can Factor V Leiden and prothrombin G20210A testing in women with recurrent pregnancy loss result in improved pregnancy outcomes? Results from a targeted evidencebased review. Genet. Med. 14: 39-50. http://dx.doi.org/10.1038/gim.0b013e31822e575b

Cao Y, Xu J, Zhang Z, Huang X, et al. (2013). Association study between methylenetetrahydrofolate reductase

Genetics and Molecular Research 15 (4): gmr.15048728 
polymorphisms and unexplained recurrent pregnancy loss: a meta-analysis. Gene 514: 105-111. http://dx.doi. org/10.1016/j.gene.2012.10.091

den Heijer M, Rosendaal FR, Blom HJ, Gerrits WB, et al. (1998). Hyperhomocysteinemia and venous thrombosis: a metaanalysis. Thromb. Haemost. 80: 874-877.

Flores-Alatriste JD, Jacobo-Nájera S, Segura-Rodríguez R and Stern-Colin y Nunes JJ (2014). Patients with inherited trombophilia and recurrent pregnancy loss: incidence. Ginecol. Obstet. Mex. 82: 383-388.

Frosst P, Blom HJ, Milos R, Goyette P, et al. (1995). A candidate genetic risk factor for vascular disease: a common mutation in methylenetetrahydrofolate reductase. Nat. Genet. 10: 111-113. http://dx.doi.org/10.1038/ng0595-111

Isordia I, Leaños A, Sainz I, Reyes E, et al. (2009). Asociación entre el polimorfismo 4G/5G en el gen del inhibidor del activador del plasminógeno-1 (PAI-1) y el infarto agudo de miocardio con elevación del ST en pacientes jóvenes. Rev. Esp. Cardiol. 62: 365-372. http://dx.doi.org/10.1016/S0300-8932(09)70893-0

Kiwi R (2006). Recurrent pregnancy loss: evaluation and discussion of the causes and their management. Cleve. Clin. J. Med. 73: 913-921. http://dx.doi.org/10.3949/ccjm.73.10.913

Mello G, Parretti E, Gensini F, Sticchi E, et al. (2003). Maternal-fetal flow, negative events, and preeclampsia: role of ACE I/D polymorphism. Hypertension 41: 932-937. http://dx.doi.org/10.1161/01.HYP.0000063146.40351.AD

Miller SA, Dykes DD and Polesky HF (1988). A simple salting out procedure for extracting DNA from human nucleated cells. Nucleic Acids Res. 16: 1215. http://dx.doi.org/10.1093/nar/16.3.1215

Mtiraoui N, Zammiti W, Ghazouani L, Braham NJ, et al. (2006). Methylenetetrahydrofolate reductase C677T and A1298C polymorphism and changes in homocysteine concentrations in women with idiopathic recurrent pregnancy losses. Reproduction 131: 395-401. http://dx.doi.org/10.1530/rep.1.00815

Nair RR, Khanna A, Singh R and Singh K (2013). Association of maternal and fetal MTHFR A1298C polymorphism with the risk of pregnancy loss: a study of an Indian population and a meta-analysis. Fertil. Steril. 99: 1311-1318.e4. http://dx.doi.org/10.1016/j.fertnstert.2012.12.027

Nelen WL, Blom HJ, Steegers EA, den Heijer M, et al. (2000). Hyperhomocysteinemia and recurrent early pregnancy loss: a meta-analysis. Fertil. Steril. 74: 1196-1199. http://dx.doi.org/10.1016/S0015-0282(00)01595-8

Preston FE, Rosendaal FR, Walker ID, Briët E, et al. (1996). Increased fetal loss in women with heritable thrombophilia. Lancet 348: 913-916. http://dx.doi.org/10.1016/S0140-6736(96)04125-6

Quintero-Ramos A, Valdez-Vélázquez LL, Hernández G, Baltazar LM, et al. (2006). Assessment of five thrombophilic genetic polymorphisms among couples with habitual abortion. Gac. Med. Mex. 142: 95-98.

Rai V (2014). Methylenetetrahydrofolate reductase gene A1298C polymorphism and susceptibility to recurrent pregnancy loss: a meta-analysis. Cell. Mol. Biol. 60: 27-34.

Rey E, Kahn SR, David M and Shrier I (2003). Thrombophilic disorders and fetal loss: a meta-analysis. Lancet 361: 901 908. http://dx.doi.org/10.1016/S0140-6736(03)12771-7

Rigat B, Hubert C, Corvol P and Soubrier F (1992). PCR detection of the insertion/deletion polymorphism of the human angiotensin converting enzyme gene (DCP1) (dipeptidyl carboxypeptidase 1). Nucleic Acids Res. 20: 1433. http:// dx.doi.org/10.1093/nar/20.6.1433-a

Ripoll L, Paulin D, Thomas S and Drouet LO (1997). Multiplex PCR-mediated site-directed mutagenesis for one-step determination of factor V Leiden and G20210A transition of the prothrombin gene. Thromb. Haemost. 78: 960-961.

Rodríguez-Guillén MdelR, Torres-Sánchez L, Chen J, Galván-Portillo M, et al. (2009). Maternal MTHFR polymorphisms and risk of spontaneous abortion. Salud Publica Mex. 51: 19-25.http://dx.doi.org/10.1590/S0036-36342009000100006

Rosenberg RD and Aird WC (1999). Vascular-bed-specific hemostasis and hypercoagulable states. N. Engl. J. Med. 340: 1555-1564. http://dx.doi.org/10.1056/NEJM199905203402007

Rosendaal FR (1999). Venous thrombosis: a multicausal disease. Lancet 353: 1167-1173. http://dx.doi.org/10.1016/ $\underline{\mathrm{S} 0140-6736(98) 10266-0}$

Samli H, Demir BC, Ozgöz A, Atalay MA, et al. (2012). Vascular endothelial growth factor gene 1154 G/A, 2578 C/A, $460 \mathrm{C} / \mathrm{T}, 936 \mathrm{C} / \mathrm{T}$ polymorphisms and association with recurrent pregnancy losses. Genet. Mol. Res. 11: 4739-4745. http://dx.doi.org/10.4238/2012.December.17.6

Sotiriadis A, Makrigiannakis A, Stefos T, Paraskevaidis E, et al. (2007). Fibrinolytic defects and recurrent miscarriage: a systematic review and meta-analysis. Obstet. Gynecol. 109: 1146-1155. http://dx.doi.org/10.1097/01. AOG.0000260873.94196.d6

Su MT, Lin SH, Chen YC and Kuo PL (2013). Genetic association studies of ACE and PAI-1 genes in women with recurrent pregnancy loss: a systematic review and meta-analysis. Thromb. Haemost. 109: 8-15. http://dx.doi. org/10.1160/TH12-08-0584

Thomas VV and van der Spuy ZM (2010). Recurrent pregnancy loss. O. G. Forum 20: 133-137.

van der Put NM, Gabreëls F, Stevens EM, Smeitink JA, et al. (1998). A second common mutation in the methylenetetrahydrofolate reductase gene: an additional risk factor for neural-tube defects? Am. J. Hum. Genet. 62:

Genetics and Molecular Research 15 (4): gmr.15048728 
1044-1051. http://dx.doi.org/10.1086/301825

Wang Z, Wang P, Wang X, He X, et al. (2013). Significant association between angiotensin-converting enzyme gene insertion/deletion polymorphism and risk of recurrent miscarriage: a systematic review and meta-analysis. Metabolism 62: 1227-1238. http://dx.doi.org/10.1016/j.metabol.2013.03.003

Weisberg I, Tran P, Christensen B, Sibani S, et al. (1998). A second genetic polymorphism in methylenetetrahydrofolate reductase (MTHFR) associated with decreased enzyme activity. Mol. Genet. Metab. 64: 169-172. http://dx.doi. org/10.1006/mgme.1998.2714

Zetterberg H, Regland B, Palmér M, Ricksten A, et al. (2002). Increased frequency of combined methylenetetrahydrofolate reductase C677T and A1298C mutated alleles in spontaneously aborted embryos. Eur. J. Hum. Genet. 10: 113-118. http://dx.doi.org/10.1038/sj.ejhg.5200767

Genetics and Molecular Research 15 (4): gmr.15048728 